\title{
The rising trend for caesarean birth
}

\author{
Britain could learn from the Netherlands
}

Obstetric interventions-especially caesarean sections-have increased in recent years in all countries of the Western World. In September a book was published on caesarean birth in Britain, with data and comment important not only for obstetricians, general practitioners, and midwives but also for those who make health policy and for pregnant women. ${ }^{1}$ The authors recently stated that the British caesarean section rate seemed to have reached a plateau at $12 \%$ in the late $1980 \mathrm{~s}^{2}$ but now they conclude that the rate increased to over $13 \%$ in 1992 , with considerable variation among the regions. ${ }^{1}$

The rates in Britain are still moderate compared with those in the United States, where attempts have been made since 1981 to halt the rise by making recommendations about breech deliveries, deliveries after a previous caesarean section, and fetal monitoring. ${ }^{3}$ Despite these initiatives the rate increased from $13.7 \%$ in 1977 to $24.7 \%$ in 1988 . In many European countries the rates are between $10 \%$ and $20 \%$.

When asked about the reasons for the change in the incidence of caesarean section British obstetricians gave some positive answers: caesarean sections are safer these days and better care has improved fetal survival. ${ }^{1}$ Some of the reasons were negative, and in this group the largest single factor, mentioned by almost half the consultants, was litigation. Some caesarean sections are performed mainly because doctors are frightened of being sued. Two of the most controversial indications are elective caesarean delivery for breech presentation and repeat caesarean section. Opinion remains divided in the British obstetric profession over these issues despite the many studies that support a trial of labour after a previous caesarean delivery ${ }^{45}$ and the fact that elective caesarean section for breech presentation has never been shown to be superior to selective vaginal delivery. ${ }^{67}$

Some obstetricians may ask why a few more caesarean sections should be seen as a problem when the risk of surgery for the patient has gone down and the risk of not performing the operation rests completely with the doctor, who might be sued if the outcome of delivery is unsatisfactory. There are several valid answers.

Firstly, though the risk of the operation has decreased, mortality is still much higher after abdominal than after vaginal delivery, and maternal morbidity and discomfort after caesarean section are not negligible. Secondly, some women, especially those who had an emergency section previously, see an elective caesarean section as a positive experience, but many-and particularly those having an emergency operation -have complaints about the postoperative pain, feelings of loss through not having been able to give birth naturally, and being separated from their babies directly after birth. Women also comment adversely about the lengthy recovery period and not being able to be up and about with their baby.

The third reason why we should try to keep the rate of obstetric interventions at the necessary minimum is more fundamental. By contrast with almost all other medical specialties, obstetrics deals to a large extent with physiology. Medical interventions aim at preventing or correcting pathological processes, not at improving physiology. A high rate of caesarean section indicates that some of these operations are interfering with physiology rather than correcting pathological conditions. In many hospitals the management of labour hardly differs between pregnant women at high and low risk. In particular, the methods of monitoring the fetus are the same. Monitors are only limited diagnostic tools with a low specificity sometimes producing false positive signals of fetal distress. In a population with a low incidence of abnormalities a high number of false positive signals may be expected-and this will lead to unnecessary interventions. This has been observed in several studies. ${ }^{8-10}$

There is an alternative approach-careful differentiation during pregnancy of high risk and low risk groups of pregnant women with different management of labour. The low risk group may be attended during labour by primary care attendants (midwives and general practitioners) without electronic monitoring but with strict criteria for referral. This, basically, is the system of care in the Netherlands. The fact that independent primary care attendants are responsible for the care during labour of pregnant women at low risk probably explains the relatively low rate of caesarean section in the Netherlands. ${ }^{11} 12$ The latest figure was $7.9 \%$ in $1991 . .^{13}$ The rate is increasing, but more slowly than in most other European countries.

In Britain caesarean section rates are higher than those in the Netherlands but certainly not as high as those in some other Western countries. By contrast with practice in the United States and several European countries, in Britain there has always been a strong role for the midwife, who is the senior professional present for at least three quarters of births. In some regions the general practitioner plays a bigger part in obstetric care than is the case in the United States or Germany. The House of Commons health committee has called for more freedom of choice for consumers, with the 
option of smaller rural maternity units and units managed by midwives for low risk cases. ${ }^{14}$ The Expert Maternity Group has also proposed comprehensive antenatal and natal care by small teams of midwives for women with uncomplicated pregnancies. ${ }^{15} 16$

Caesarean Birth in Britain makes recommendations in line with these reports: more information on possible places of birth and packages of maternity care and smaller teams of midwives to look after identified caseloads of women throughout their pregnancy, birth, and the postnatal period. ${ }^{1}$ A more critical attitude by obstetricians may well help to avoid unnecessary interventions, though it may be just as important to have an organisation providing maternity care

1 Francome C, Savage W, Churchill H, Lewison H. Caesarean Birth in Britain. Middlesex University Press, 1993.

2 Savage $\mathrm{W}$, Francome C. British caesarean section rates: have we reached a plateau? $\mathrm{Br} \boldsymbol{\mathcal { O }}$ Obstet Gynaecol 1993;100:493-6.

3 National Institutes of Health. Cesarean Childbirth. Washington, DC: US Department of Health and Human Services, Public Health Service, US Government Printing Office, 1987. (Publication No 82-2067.)

4 Coltart TM, Davies JA, Katesmark M. Outcome of a second pregnancy after a previous caesarean section. Br f Obstet Gynaecol 1990;97:1 140-3.

5 Flamm BL, Newman LA, Thomas SJ, Fallon D, Yoshida MM. Vaginal birth after cesarean delivery: results of a 5-year multicenter collaborative study. Obstet Gymecol 1990;76:750-4.

6 Keirse MINC. Preterm delivery. In: Chalmers I, Enkin M, Keirse MINC. Effective care in pregnancy and childbirth. Oxford: Oxford University Press, 1989:1270-92.

7 Bodmer B, Benjamin A, McLean FH, Usher RH. Has use of cesarean section reduced the risk of delivery in breech presentation? Am $\mathcal{O}$ Obstet Gymecol 1986;154:44-50. for low risk women by midwives dedicated to protecting physiology.

A close cooperation between midwives, general practitioners, and obstetricians, with mutual respect for each other's special abilities, is a prerequisite for such a system to work.

PIETER E TREFFERS

Emeritus professor of obstetrics and gynaecology

MARIA PEL

Academic Medical Centre,

Consultant obstetrician

Department of Obstetrics and Gynaecology,

$1105 \mathrm{AZ}$ Amsterdam,

The Netherlands

8 Neilson JP. Cardiotocography during labour. $B M \Im$ 1993;306:347-8.

9 Freeman R. Fetal monitoring-a disappointing story. N Engl F Med 1990;3:624-6.

10 Grant A. Monitoring the fetus during labour. In: Chalmers I, Enkin M, Keirse MJNC eds. Effective care in pregnancy and childbirth. Oxford: Oxford University Press, 1989: 846-82.

11 Van Alten D, Eskes $M$, Treffers PE. Midwifery in the Netherlands. The Wormerveer study: selection, mode of delivery, perinatal mortality and infant morbidity. $\mathrm{Br} \mathcal{O}$ Obstet Gynaecol 1989;96:656-62.

12 Treffers PE, Eskes $M$, Kleiverda G, Van Alten D. Home births and minimal medical interventions. IAMA 1990;264:2203-8.

13 SIG Zorginformatie. faarboek verloskunde 1991. Utrecht: SIG, 1992.

14 Select Committee on Health. Second report. Maternity services. London: HMSO, 1992

15 Expert Maternity Group. Changing childbirth. London: HMSO, 1993.

16 Lilford R. Midwives to manage uncomplicated childbirth. BMF 1993;307:339-40.

\section{Can we afford the welfare state?}

\section{We can't afford not to have it}

Several recent articles in the $B M \Im$ have drawn attention to an apparent fiscal crisis in welfare states throughout Europe. In the Netherlands "the cabinet is determined to push ahead with the harshest cuts in the country's welfare system since the second world war." In France the government is to reduce the reimbursement that patients can claim for medical treatment and drugs, while raising the level of social security contributions. ${ }^{23}$ In Germany sickness pay is to be restricted, and cuts in other benefits are being mooted. ${ }^{4}$

Britain is no exception to this atmosphere of crisis. Dire warnings issue almost daily from cabinet ministers about the size and growth of the public deficit and the need to rein it back, preferably by cutting or eliminating key areas of spending on welfare. Peter Lilley, secretary of state for social security, has even produced a public document arguing that his department spends too much. ${ }^{5}$ Although few people, in or out of government, argue that the NHS needs cutting back, the government's latest expenditure plans suggest that the growth in NHS spending is to be sharply reduced, almost certainly below that necessary to keep pace with the growth in demand. ${ }^{6}$

But the apparent universality of this "crisis" is misleading. Many of the problems in continental Europe are specific to the country concerned. Germany is struggling with the costs of reunification. The Dutch have a particular problem with their equivalent of invalidity benefit, now being claimed by one sixth of their working population. France is suffering from massive unemployment generated by the "franc fort" policy. And all these countries are moving into recession.

So does Britain, too, have a welfare crisis? It is pulling out of recession, so that is less of a problem, but there are two other worries. One is apparently excessive spending on welfare in the short term, which is contributing to large deficits in the public sector ( $£ 50$ billion is estimated for the current fiscal year). The second is much longer term: ever increasing demands being placed on the welfare system by demographic and economic factors, such as the increase in single parents and - of more interest from a health perspective - the aging of the population.

The first point to note about the short term deficit is that, in so far as there is a problem, it is partly self induced. In the two years preceding the election the government increased spending by nearly $£ 40$ billion; for the NHS alone, resources increased by $12 \%$ in real terms ${ }^{6}$ (which probably goes a long way to explain the recent increases in activity rates in the NHS that have instead been attributed to the reforms).

Secondly, and more importantly, it is far from clear that spending on welfare is out of control. It is true that, in the three years up to 1992-3, the share of the gross domestic product taken up by public expenditure on health, personal social services, education, housing, and social security rose from $21.4 \%$ to $26.4 \%$. But this was partly due to the fall in the gross domestic product induced by the recession. Moreover, even the figure for 1992-3 is not excessive in historical terms. Since 1973, expenditure on welfare has fluctuated but has always remained between $22 \%$ and $26 \%$ of the gross domestic product. ${ }^{2}$

The long term problem is also exaggerated, particularly so far as aging is concerned. The numbers of elderly people in Britain will rise in the 20 years from 1991 to 2011 by less than half the increase that has already happened since 1971. The numbers rise more sharply after 2011 (particularly for those over 75), but, even by 2041 , four fifths of the population will still be aged below 65 . The estimated age dependency ratio (the number of people aged over 65 for every 100 aged 15-64) shows no great change until 2020, remaining at around 25; by 2040 it will have increased to 33.1 , but even then it will be well below that faced by other advanced countries, including 